\title{
Craniosynostosis in NSW
}

Lee Taylor, Acting Manager, Maternal and Child Health, Epidemiology and Health Services Evaluation Branch, NSW Health Department.

Isla Tooth, Senior Policy Planning Officer,

Health Promotion Unit, Central Sydney Area Health Service.

Craniosynostosis is the premature closing of the cranial sutures in childhood. When a single suture is involved craniosynostosis results in an abnormally shaped skull. When multiple sutures are involved brain development may be affected as well, resulting in developmental delay. In early 1993 the AIHW National Perinatal Statistics Unit noted an increase in the reported number of cases of craniosynostosis in NSW in 1990 compared with previous years. A study was carried out to determine whether a true increase in incidence had occurred. Over the period 19881991 there was a rise in the incidence of craniosynostosis in NSW from 6.6 to $9.8 / 10,000$ births, with an average of $8.1 / 10,000$. The increase was not statistically significant. The rate of craniosynostosis is slightly higher in the South Eastern Region and Western Sydney Area compared with NSW as a whole due to the referral of relatively large numbers of children with a single lambdoid synostosis for assessment and/or surgery.

n February 1993 the AIHW National Perinatal Statistics Unit (NPSU) noted an increased rate of reporting of craniosynostosis in NSW for 1990 compared with previous years $(8.6 / 10,000 \text { births compared with } 1.0 / 10,000 \text { births })^{1}$. This rate was about five times higher than in the other States.

Before 1990 the NPSU was responsible for the collection and reporting of data on birth defects in NSW. The NPSU surveillance system included birth defects detected during pregnancy and up to 28 days of life. During 1989 the NSW Birth Defects Register (BDR) was established and surveillance of birth defects in NSW was transferred to the NSW Health Department. The BDR includes birth defects detected during pregnancy and up to one year of age.

While the increase in reporting of cases of craniosynostosis for 1990 could be explained by this change in the upper age limit for reporting of cases, a study was undertaken to determine whether there has been a real rise in the incidence of craniosynostosis in NSW.

\section{METHODOLOGY}

After obtaining permission from the hospital administration, cases of craniosynostosis were identified through review of medical records at The Prince of Wales Children's Hospital, The Children's Hospital, Camperdown, Westmead Hospital and The John Hunter Hospital.

Medical records for children who fulfilled the following criteria were reviewed:

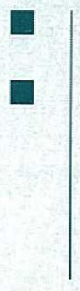

born between January 1988 and December 1992; and

discharged with a 7560 ICD9CM code between January 1, 1988 and December 31, 1992 from one of the following hospitals: The Prince of Wales Children's Hospital, The Children's Hospital, Camperdown, Westmead Hospital or The John Hunter Hospital.
A case of craniosynostosis was defined by either: corrective surgery for craniosynostosis; or radiological confirmation of craniosynostosis either by radiological report or documentation of radiological confirmation in the medical admission notes.

Data were collected on demographic factors, type of delivery, birthweight, gestational age, family history, other birth defects, age at diagnosis and surgery (where applicable). Additional birth defects were recorded if they met the definition of a major birth defect as applied by the $\mathrm{BDR}^{2}$.

Data were entered onto an EpiInfo database and univariate analysis was carried out using SAS software. Calculations for rates were based on the data for the years 1988-1991, as cases of craniosynostosis among infants born in 1992 may not be diagnosed until 1993 or later. Denominator populations for rates for the years 1988-1991 were obtained from the Australian Bureau of Statistics (ABS) ${ }^{3}$. Denominator rates for NSW Health Areas and Regions were obtained from the 1990 NSW Midwives Data Collection (MDC) ${ }^{4}$ as a midpoint of the four-year period. Poisson confidence intervals around rates were calculated using the method described by Daly ${ }^{5}$. Analyses other than rates were based on craniosynostosis cases from the full 1988-92 period and data from the $1990 \mathrm{MDC}$ for comparative purposes. Tests of significance were carried out using a chi-squared test for comparison of proportions and a t-test for comparison of means with a 5 per cent significance level as the cut-off point.

\section{RESULTS}

Nine hundred and ninety-eight medical records met the criteria for review. Ninety-nine per cent were available for review. A total of 346 records met the case definition.

There was a small, but non-significant, increase in the occurrence of craniosynostosis cases in NSW from 6.6 to 9.8/10,000 livebirths between 1988 and 1991 (Table 2). This increase is largely due to an increased number of children with a single lambdoid craniosynostosis referred to hospital for assessment and/or treatment (Table 3).

The incidence of craniosynostosis varied from $2.4 / 10,000$ births in the North Coast Region to 21.4/10,000 births in the South Eastern Region (Table 4). The South Eastern Region and Western Sydney Area had incidences of craniosynostosis significantly higher than NSW as a whole, while the North Coast Region had a lower rate than NSW as a whole. The excess of cases in the South Eastern Region and Western Sydney Area is due to the referral of relatively large numbers of children with single lambdoid synostoses (Table 5).

Among the 346 cases identified, 237 ( 68.5 per cent) were males and 109 ( 31.5 per cent) were females. The proportion of males affected is significantly higher than expected when compared with the sex distribution of NSW births $\left(\mathrm{X}^{2}=39.4, \mathrm{p}<0.001\right)$.

Information on maternal age was available for 287 cases ( 82.9 per cent) and usually related to the mother's age at the time of the child's first admission. Average maternal age was 29.3 years. This is not significantly different from the average maternal age in NSW of 28.4 years. Paternal age was available for 280 cases ( 80.9 per cent). Average paternal age was 32.2 years. There are no data available on paternal age in NSW for comparative purposes. 
TABLE 2

CRANIOSYNOSTOSIS CASES BY YEAR OF BIRTH,

NSW, 1988-1992

\begin{tabular}{|llll|}
\hline Year of birth & $\begin{array}{l}\text { Number } \\
\text { (a) }\end{array}$ & $\begin{array}{l}\text { Rate per 10,000 } \\
\text { livebirths (b) }\end{array}$ & $\begin{array}{l}\text { 95\% confidence } \\
\text { interval }\end{array}$ \\
\hline 1988 & 56 & 6.6 & $5.0-8.6$ \\
1989 & 60 & 7.0 & $5.3-9.0$ \\
1990 & 75 & 8.3 & $6.5-10.4$ \\
1991 & 86 & 9.8 & $7.8-12.2$ \\
1992 & 68 & (c) & \\
\hline
\end{tabular}

Notes:

(a) Excludes one case where information on date of birth was not available.

(b) Denominator births for rates were obtained from the Australian Bureau of Statistics ${ }^{3}$.

(c) The rate for 1992 was not calculated because additional cases among infants born in 1992 may not be diagnosed until 1993 or later.

\section{Craniosynostosis in NSW}

\section{Continued from page 113}

Information on type of delivery was available for 332 cases (96.0 per cent). Of these, 228 (68.7 per cent) were reported as having been born by normal vaginal delivery, 65 (19.6 per cent) by caesarean section, 33 ( 9.9 per cent) by instrumental delivery and six ( 1.8 per cent) by vaginal breech delivery. There was no significant difference between the pattern of type of delivery among craniosynostosis cases and NSW births as a whole.

Cases were assumed to be singleton births unless otherwise recorded. There were 335 singleton births, 10 twins and one triplet. Of cases, 3.2 per cent were multiple births. The proportions of singleton and multiple births are not significantly different from NSW births.

Information on birthweight was available for 317 cases (91.6 per cent). The average birthweight of cases was 3,346 grams. This is not significantly different from the average birthweight in NSW of 3,358 grams.

Information on gestational age at birth was available for 335 cases ( 96.8 per cent). The average gestational age of cases was 39.3 weeks. This is not significantly different from the average gestational age in NSW of 39.2 weeks.

The age at diagnosis of craniosynostosis was recorded for 242 cases ( 69.9 per cent). The age at diagnosis ranged from 0 to 16 months, the average age being 1.7 months. Ninetyseven cases (28.2 per cent) were diagnosed at birth or in the first month of life, and 67.9 per cent were diagnosed by six months of age. Only two cases were diagnosed after 12 months of age.

Among the 346 children affected there were 368 craniosynostoses because some children had more than one suture involved. The overall distribution of suture involvement was as follows: coronal 48 (19.8 per cent), sagittal 98 (28.3 per cent), lambdoid 195 (56.4 per cent) and metopic 27 ( 7.8 per cent).

Multiple sutures were involved in 48 cases (13.9 per cent). This includes cases with bilateral involvement of coronal or lambdoid sutures. Single suture involvement accounted for the remaining 86.1 per cent of cases and was distributed as follows: coronal 23 ( 6.6 per cent), sagittal 85 ( 24.6 per cent), lambdoid 167 (48.3 per cent) and metopic 21 (6.1 per cent).

In 93.1 per cent of cases craniosynostosis was the only birth defect present. In eight cases it was part of a known syndrome: Crouzon syndrome (4), Pfeiffer syndrome (2), Apert syndrome (1) and Saethre-Chotzen syndrome (1), all of which are associated with autosomal dominant inheritance. One further case had Goldenhar syndrome, which does not usually feature craniosynostosis.

Birth defects in addition to craniosynostosis were present in 24 cases ( 6.9 per cent). Of these, five were associated with syndromes described above. In the remaining 19 infants, an additional 22 defects were reported: anomalies of brain development (5), anomalies of the heart and great vessels (6), musculoskeletal anomalies (3), anomalies of larynx/ trachea (3), renal anomalies (2), cleft lip/palate (2), other (1).

Craniosynostosis was reported among three parents of children with craniosynostosis. In each it was related to syndromes with known autosomal dominant inheritance (Crouzon syndrome 2, Saethre-Chotzen syndrome 1).

Of the 347 cases, 247 ( 71.4 per cent) were reported to have siblings. Of these siblings, 16 ( 6.5 per cent) were reported to have craniosynostosis, including one family where two siblings were affected. In only one of these families was the index child reported as having an autosomal dominant inherited condition.

The surgery rate for cases was 98.0 per cent. Sixty-six cases had two operations and 17 cases had three or more operations. The age at first operation ranged from one to 24 months, with an average of five months.

\section{DISCUSSION}

Craniosynostosis usually occurs as an isolated primary birth defect. It may be associated with a recognised syndrome, microcephaly, shunt operations for hydrocephalus, metabolic diseases (such as hyperthyroidism, rickets, mucopolysaccharidoses, mucolipidoses), haematologic disorders (such as thalassaemias, sickle cell anaemia, congenital haemolytic jaundice, polycythemia vera) and exposure to certain medications (for example, aminopterin, diphenylhydantoin, retinoic acid and valproic acid). There is some evidence that foetal head constraint in utero may cause craniosynostosis ${ }^{6}$.

In current practice a child with multiple craniosynostoses which are not related to an underlying deficiency in cerebral development (such as microcephaly) will be referred for surgical correction in order to prevent developmental disability. Surgery has been recommended as early as four to six weeks of age on the basis of rapid rate of bone growth in the first six months and the relative ease of surgical bone remodelling in the early weeks of life compared with later ages $^{7.8}$. The possibility of developmental disability and raised intracranial pressure occurring from the premature closure 


\section{TABLE 3}

CRANIOSYNOSTOSIS CASES BY TYPE OF SUTURE INVOLVEMENT AND YEAR OF BIRTH، 1988-1991 (A)

\begin{tabular}{|c|c|c|c|c|c|c|c|c|c|c|c|c|}
\hline \multirow{3}{*}{$\begin{array}{l}\text { Year of birth } \\
1988\end{array}$} & \multirow{2}{*}{\multicolumn{2}{|c|}{$\begin{array}{r}\text { Multiple rate/ } \\
10,000\end{array}$}} & \multirow{2}{*}{\multicolumn{2}{|c|}{$\begin{array}{r}\text { Coronal rate/ } \\
10,000\end{array}$}} & \multirow{2}{*}{\multicolumn{2}{|c|}{$\begin{array}{r}\text { Suture inv } \\
\text { Sagittal rate/ } \\
10,000\end{array}$}} & ent & & \multirow{2}{*}{\multicolumn{2}{|c|}{$\begin{array}{r}\text { Metopic rate/ } \\
10,000\end{array}$}} & \multirow{2}{*}{\multicolumn{2}{|c|}{$\begin{array}{r}\text { Total rate/ } \\
10,000\end{array}$}} \\
\hline & & & & & & & \multicolumn{2}{|c|}{$\begin{array}{r}\text { Lambdoid rate/ } \\
10,000\end{array}$} & & & & \\
\hline & 9 & 4.0 & 4 & 1.8 & 15 & 7.0 & 23 & 9.9 & 5 & 1.9 & 56 & 24.6 \\
\hline 1989 & 12 & 4.4 & 3 & 0.9 & 12 & 6.5 & 29 & 15.2 & 4 & 3.0 & 60 & 30.0 \\
\hline 1990 & 6 & 3.9 & 6 & 2.5 & 21 & 7.6 & 34 & 15.2 & 6 & 3.4 & 75 & 34.3 \\
\hline 1991 & 18 & 9.3 & 8 & 4.8 & 17 & 7.5 & 40 & 18.9 & 3 & 1.1 & 86 & 41.6 \\
\hline
\end{tabular}

Note:

(A) Excludes one case where information on date of birth was not available. Denominator births for rates were obtained from the

Australian Bureau of Statistics ${ }^{3}$.

\section{TABLE 4}

INCIDENCE OF CRANIOSYNOSTOSIS CASES BY NSW HEALTH AREA/REGION OF RESIDENCE, 1988-1991

\begin{tabular}{|lccc|}
\hline Health Area/Region & $\begin{array}{c}\text { Average no. of } \\
\text { cases per year }\end{array}$ & $\begin{array}{c}\text { Rate per 10,000 } \\
\text { livebirths (a) }\end{array}$ & $\begin{array}{c}99 \% \text { confidence } \\
\text { interval }\end{array}$ \\
\hline Central Sydney & 4.3 & 9.2 & $4.4-16.6$ \\
Eastern Sydney & 2.3 & 6.4 & $2.2-14.2$ \\
South Western Sydney & 7.5 & 6.9 & $4.1-10.8$ \\
Western Sydney & 13.3 & 14.0 & $9.5-19.7$ \\
Southern Sydney & 3.5 & 4.5 & $2.0-8.7$ \\
Northern Sydney & 10.5 & 12.7 & $8.2-18.7$ \\
Wentworth & 5.0 & 9.8 & $5.1-17.0$ \\
Central Coast & 2.8 & 7.6 & $3.0-15.7$ \\
Hunter & 3.0 & 4.1 & $1.7-8.3$ \\
Illawarra & 2.8 & 5.9 & $2.3-12.2$ \\
New England Region & 2.3 & 6.0 & $2.1-13.4$ \\
South Eastern Region & 5.8 & 21.4 & $11.7-35.8$ \\
North Coast Region & 1.3 & 2.4 & $0.5-6.8$ \\
Orana and Far West Region & 2.8 & 11.4 & $4.5-23.7$ \\
Central Western Region & 1.3 & 4.7 & $1.0-13.2$ \\
South West Region & 1.3 & 3.3 & $0.7-9.4$ \\
NSW & 69.3 & 8.1 & $6.9-9.4$ \\
\hline
\end{tabular}

Note:

(a) Denominator births for rates were obtained from the NSW Midwives Data Collection ${ }^{4}$ for 1990 as the mid-point for the four-year period.

\section{TABLE 5}

CRANIOSYNOSTOSIS BY TYPE OF SUTURE INVOLVEMENT AND HEALTH AREA/REGION OF RESIDENCE, 1988-1991 (A)

\begin{tabular}{|c|c|c|c|c|c|c|c|c|c|c|c|c|}
\hline \multirow{2}{*}{\multicolumn{3}{|c|}{$\begin{array}{l}\text { Health Area/Region } \\
\text { Multiple rate/ } \\
10,000\end{array}$}} & \multirow{2}{*}{\multicolumn{2}{|c|}{$\begin{array}{r}\text { Coronal rate/ } \\
10,000\end{array}$}} & \multicolumn{4}{|c|}{ Suture involvement } & \multirow{2}{*}{\multicolumn{2}{|c|}{$\begin{array}{r}\text { Metopic rate/ } \\
10,000\end{array}$}} & \multirow{2}{*}{\multicolumn{2}{|c|}{$\begin{array}{r}\text { Total rate } \\
10,000\end{array}$}} \\
\hline & & & & & \multicolumn{2}{|c|}{$\begin{array}{r}\text { Sagittal rate/ } \\
10,000\end{array}$} & \multicolumn{2}{|c|}{$\begin{array}{r}\text { Lambdoid rate/ } \\
10,000\end{array}$} & & & & \\
\hline Central Sydney & 3 & 1.6 & 1 & 0.5 & 2 & 1.1 & 10 & 5.4 & 1 & 0.5 & 17 & 9.2 \\
\hline Eastern Sydney & 1 & 0.7 & 1 & 0.7 & 2 & 1.4 & 4 & 2.8 & 1 & 0.7 & 9 & 6.4 \\
\hline South Western Sydney & y 6 & 1.4 & 2 & 0.5 & 11 & 2.5 & 9 & 2.1 & 2 & 0.5 & 30 & 6.9 \\
\hline Western Sydney & 4 & 1.1 & 5 & 1.3 & 9 & 2.4 & 35 & 9.2 & 0 & 0.0 & 53 & 14.0 \\
\hline Southern Sydney & 1 & 0.3 & 1 & 0.3 & 5 & 1.6 & 6 & 1.9 & 1 & 0.3 & 14 & 4.5 \\
\hline Northern Sydney & 9 & 2.7 & 1 & 0.3 & 6 & 1.8 & 22 & 6.7 & 4 & 1.2 & 42 & 12.7 \\
\hline Wentworth & 5 & 2.5 & 1 & 0.5 & 6 & 2.9 & 6 & 2.9 & 2 & 1.0 & 20 & 9.8 \\
\hline Central Coast & 0 & 0.0 & 2 & 1.4 & 2 & 1.4 & 5 & 3.5 & 1 & 0.7 & 11 & 7.7 \\
\hline Hunter & 3 & 1.0 & 2 & 0.7 & 6 & 2.1 & 1 & 0.3 & 0 & 0.0 & 12 & 4.1 \\
\hline Illawarra & 3 & 1.6 & 1 & 0.5 & 4 & 2.1 & 1 & 0.5 & 2 & 1.1 & 11 & 5.9 \\
\hline New England Region & 3 & 2.0 & 0 & 0,0 & 2 & 1.3 & 2 & 1.3 & 2 & 1.3 & 9 & 6.0 \\
\hline South Eastern Region & 3 & 2.8 & 1 & 0.9 & 3 & 2.8 & 16 & 14.9 & 0 & 0.0 & 23 & 21.4 \\
\hline North Coast Region & 0 & 0.0 & 1 & 0.5 & 3 & 1.4 & 1 & 0.5 & 0 & 0.0 & 5 & 2.4 \\
\hline Orana and Far West & & & & & & & & & & & & \\
\hline Region & 2 & 2.1 & 1 & 1.0 & 2 & 2.1 & 4 & 4.2 & 1 & 1.0 & 11 & 11.4 \\
\hline Central West Region & 2 & 1.9 & 0 & 0.0 & 1 & 0.9 & 1 & 0.9 & 1 & 0.9 & 5 & 4.7 \\
\hline South West Region & 0 & 0.0 & 1 & 0.7 & 1 & 0.7 & 3 & 2.0 & 0 & 0.0 & 5 & 3.3 \\
\hline NSW & 45 & 21.6 & 21 & 9.9 & 65 & 28.6 & 127 & 59.4 & 18 & 9.3 & 277 & 130.4 \\
\hline
\end{tabular}

Note:

(A) Rates per 10,000 livebirths. Denominator births for rates were obtained from the NSW Midwives Data Collection ${ }^{4} 1990$ as the mid-point for the four-year period. 


\section{Craniosynostosis in NSW}

Continued from page 114

of a single suture has not been convincingly shown ${ }^{7}$. However, children with single suture involvement will frequently be referred for surgery for cosmetic reasons and to prevent psychological problems in later life.

Craniosynostosis accounts for about 4.5 per cent of reported major birth defects in $\mathrm{NSW}^{2}$. In this study, craniosynostosis was found to occur about twice as frequently among males as females. This has been noted previously by Alderman et al, who found males were affected about one and a half times more frequently than females ${ }^{9}$. Craniosynostosis cases did not differ from the population of births in NSW in 1990 for type of delivery, maternal age, gestational age at birth or birthweight.

The incidence of craniosynostosis was found to be $8.1 / 10,000$ livebirths over the period 1988-1991. This is consistent with rates reported elsewhere, which vary from 3 to $26 / 10,000$ births $^{9,10}$. As only about one-quarter of craniosynostosis cases are detected in the first month of life, the increase in the reported rate of craniosynostosis in NSW is almost certainly due to the change in the upper age limit for reporting of birth defects in NSW in 1989, from 28 days to one year.

The most common suture involvement was synostosis of a single lambdoid suture. This differs from the two published case series where a single sagittal suture synostosis was most common ${ }^{9,11}$.

The rate of craniosynostosis was found to be higher in the South Eastern Region and Western Sydney Area. This is due to the referral of relatively large numbers of children with single lambdoid synostosis for assessment and/or surgery. The management of a single lambdoid synostosis is based on cosmetic concern as there is no evidence that a single lambdoid synostosis causes developmental delay. As the rates of multiple suture involvement, and involvement of single coronal, sagittal, and metopic sutures are fairly uniform across NSW Health Areas and Regions, the higher rate of craniosynostosis in these two areas is likely to be due to differences in clinical management practice, with a higher rate of surgical correction for milder degrees of lambdoid synostosis, rather than a real difference in the incidence of craniosynostosis.

\footnotetext{
1. AIHW National Perinatal Statistics Unit. Congenital Malformations No 47 July-September 1992 . University of Sydney, December 1992 2. Kemp T, Taylor L, Nguyen R, Frommer M. NSW Birth Defects Register: 1990 Report. NSW Health Department, 1993.

3. Australian Bureau of Statistics. 1991 Demography New South Wales. Catalogue No $3311.1,1993$.

4. NSW Midwives Data Collection, Epidemiology and Health Services 4. NSW Midwives Data Collection, Epidemiology

5. Daly L. Simple SAS macros for the calculation of exact binomial and poisson confidence limits. Comput Biol Med 1992; 22(5):351-361. 6. Cohen MM. Etiopathogenesis of craniosynostosis. Neurosurg Clin $N$ Am July 1991; 2(3):507-13.

7) Shillito J. A plea for early operations for craniosynostosis. Surg Neurol 7. Shillito J. A plea

8. Persing JA, Jane JA. Craniosynostosis. Sem Neurol 1989; 9(3):200-09 9. Alderman BW, Lammer EJ, Joshua SC, Cordero JF, Ouimette DR, Wilson MJ, Ferguson SW. An epidemiological study of craniosynostosis: risk indicators for the occurrence of craniosynostosis in Colorado. Am J Epidemiol 1988; 128(2):431-8.

10. French LR, Jackson IT, Melton LJ. A population-based study of craniosynostosis. J Clin Epidemiol 1990; 43(1):69-73.

11. Shillito J, Matson DD. Craniosynostosis: a review of 519 surgical patients. Pediatrics 1968; 41 (4):829-53.
}

\section{Planning the Welsh way}

\section{Continued from page 112}

care management, leaving them to concentrate on their planning role. Arguably, it has also opened the way to greater objectivity in resource allocation by ending the accountability that health authorities previously had for the financial performance of providers.

Health authorities in Wales are thus able to define their accountability in terms of the health status of their resident populations, in a way that Area Health Services in NSW probably cannot to the same extent, given their more direct involvement in operational health care management.

\section{RELEVANCE FOR NSW}

The planning model outlined here has been developed in response to challenges that are generic to most health systems. These issues are equally relevant for NSW, as is clearly shown by the recent report ${ }^{4}$ on health funding by the NSW Parliament's Public Accounts Committee, which calls for greater emphasis on strategic planning, outcomes and community involvement in health decision-making.

The recent NHS Wales experience shows that adopting a stronger focus on outcomes across the health system in its entirety can be an achievable goal. Moreover, this can be progressed as part of a policy that requires the system to measure its performance in terms of the contribution it makes to improving health within a defined population.

The main messages are these:

- It is important to have strong, credible leadership when reorienting the health system towards better accountability for health improvement;

The leadership must embrace direction-setting and the identification of very clear priorities for attention; A commitment to building partnerships is also essential, both in setting the direction for the system as a whole and in local decision-making;

Within a clear framework of direction and priorities, local flexibility in implementation is important to encourage responsiveness and innovation, and to build accountability for health at the community level.

1. Welsh Health Planning Forum (1989). Strategic Intent and Direction for the NHS in Wales. Welsh Office. Cardiff. Wales. UK

2. Welsh Health Planning Forum (1992). Protocol for Investment in Health Gain for Injuries. Welsh Office. Cardiff. Wales. UK.

Health Gain for Injuries. Welsh Office. Cardiff. Wales. UK.
3. Nutbeam D et al (1993). Goals and Targets for Australia's Health in the Year 2000 and Beyond. Department of Public Health, University of Sydney.

4. NSW Parliament (1993). Public Accounts Special Commitee report into the funding of health infrastructure and services in NSW. Report No. 72.

\section{PUBLIC HEALTH EDITORIAL STAFF}

The Bulletin's editorial advisory panel is as follows:

Dr Sue Morey, Chief Health Officer, Public Health Division, NSW Health Department; Professor Stephen Leeder, Director, Department of Community Medicine, Westmead
Hospital; Professor Geoffrey Berry, Head, Department of Public Health, University of Sydney; Dr Christine Bennett, General Manager, Royal Hospital for Women; Dr Michael Frommer, Deputy Director, Epidemiology and Health Services Evaluation Branch, NSW Health Department; Ms Jane Hall, Director, Centre for Health Economics Research and Evaluation; and Mr Michael Ward, Manager, Health Promotion Unit.

The editor is Dr George Rubin, Director, Epidemiology and Health Services Evaluation Branch, NSW Health Department

Articles, news and comments should be 1,000 words or less in length and include a summary of the key points to be made in the first paragraph. Please submit items in hard copy and on diskette, preferably using Wortsereet 5.1, to the editor, Public Health Bulletin, Locked Mail Bag 961, North Sydney 2059. Facsimile (02) 3919232. Please contact your local Public Health Unit to obtain copies of the NSW Public Health Bulletin. 